\title{
Direct brow lifting: Specific indications for a simplified approach to eyebrow ptosis
}

\author{
Michele Pascali, Ilaria Bocchini, Anna Avantaggiato', Francesco Carinci ${ }^{1}$, Valerio Cervelli, \\ Fabrizio Orlandi, Davide Quarato \\ Department of Plastic and Reconstructive Surgery, University of Rome Tor Vergata, Rome, ${ }^{1}$ Department of Morphology, \\ Surgery and Experimental Medicine, University of Ferrara, Ferrara, Italy
}

Address for correspondence: Dr. Ilaria Bocchini, Department of Plastic and Reconstructive Surgery, University of Rome Tor Vergata, Via Casilina 1049, Rome, Italy. E-mail: ilaria-3@live.it

\section{ABSTRACT}

Context: Brow lifting is an essential element in the rejuvenation of the ageing face. Various surgical techniques have been described. Among these, the direct brow lifting is an easy and effective technique that is often neglected because the scar can remain visible. Thus, this approach is usually reserved for elderly patients and males, with thick bushy brows. Aims: The authors present their result from a series of fifty consecutive patients treated over 2 years with direct brow lift. The aim is to demonstrate when the hairline is high or temporal alopecia is present and whether this technique is the best in bald patients, when some surgical steps are carefully adhered to. In these cases, the scar is less visible, hidden in the brow and is a good solution in women too. Subjects and Methods: Between January 2011 and January 2013, fifty patients underwent direct brow lift surgery. All were men. In all the cases, brow lifting was undertaken together with an upper blepharoplasty. The amount of brow elevation produced was assessed by comparing the vertical distances between the superior eyebrow hairline and the inter-pupillary line, pre-and post-operatively. The result and the scar quality were assessed both by the patient and the surgeon. Statistical Analysis Used: The paired $t$-test. Results: The authors obtained statistically significant results in brow elevation in $98 \%$ of the patients after a 12-month follow-up. The main complication associated with this procedure was visibility of the scar in two patients. Conclusions: The direct brow lift technique in bald men and with a high anterior hairline provides excellent and long-lasting results.

\section{KEY WORDS}

Brow asymmetry; brow lift; brow ptosis; men; periorbital rejuvenation

\section{INTRODUCTION}

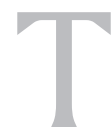

he role of attractiveness in social acceptance and self-confidence is the reason for the increasing interest in cosmetic medical and surgical

\begin{tabular}{|l|l|}
\hline \multicolumn{2}{|c|}{ Access this article online } \\
\hline Quick Response Code: & Website: \\
\hline & www.ijps.org \\
\cline { 2 - 2 } & DOI: \\
\hline
\end{tabular}

procedures for both women and men. ${ }^{[1,2]}$ Forehead and eyebrows are integral elements in facial ageing. The effects of age-related atrophy, gravity and movements of the lateral portion of the orbicularis oculi muscle, as well as

This is an open access article distributed under the terms of the Creative Commons Attribution-NonCommercial-ShareAlike 3.0 License, which allows others to remix, tweak, and build upon the work non-commercially, as long as the author is credited and the new creations are licensed under the identical terms.

For reprints contact: reprints@medknow.com

How to cite this article: Pascali M, Bocchini I, Avantaggiato A, Carinci F, Cervelli V, Orlandi F, et al. Direct brow lifting: Specific indications for a simplified approach to eyebrow ptosis. Indian $\mathrm{J}$ Plast Surg 2016;49:66-71. 
the patient's genetics, are collectively responsible for the eyebrow descent and the skin and soft tissue alterations in this area. These changes are more pronounced in the lateral than in the medial portion of the eyebrow. The ptosis of the lateral brow portion compromises its classic 'arched' shape. This contributes to an aged appearance ${ }^{[3]}$ with a sad and tired look and a pseudo-skin excess that is more pronounced in the lateral third of the upper eyelid. ${ }^{[4]}$ The shape of an ideal eyebrow has changed over time. Now, the most appreciated shape is an arch with the highest point lying directly above the lateral canthus. ${ }^{[5]}$

For the pre-surgical evaluation, it is important to assess the skin type, the position, shape and symmetry of the brows, the degree of ptosis, the presence of forehead rhytides and the position of the anterior hairline. ${ }^{[6]}$ A typically youthful forehead measures $4.5-5.5 \mathrm{~cm}$. Measurements of the upper third must deal with the balance needs of the middle and lower thirds of the face. ${ }^{[7]}$

The surgical correction includes adequate release, intra-operative brow elevation and shaping, tension-free fixation in the desired position and post-operative tissue relaxation/stretching. ${ }^{[4]}$ Multiple fixation techniques have been developed to fix the elevated brows until natural scarring stabilises the new position. Various techniques have been described, often in conjunction with the upper lid blepharoplasty, for the correction of ptotic brows (including the non-surgical ${ }^{[8]}$ ). Commonly performed are the coronal or the endoscopic approach, the anterior hairline forehead plasty (in the subgaleal, sub-periosteal or subcutaneous planes), the subcutaneous temporal, the trans-palpebral and the direct brow lifting ${ }^{[9,10]}$ Many variables are involved in selecting the best procedure for the patients, as each one of these techniques can affect the final outcome in a different way. The aim of this study is to demonstrate that the direct brow lifting is a good choice, when the brows are thick, when a global brow reshaping is required as in case of asymmetries, in bald patients or in subjects with a high anterior hairline. In fact, this technique allows a better control over the amount of elevation, thus avoiding extensive dissection, when compared to the other techniques. Moreover, the scar is less visible when brow hair is present rather than in conditions of total or partial baldness.

\section{SUBJECTS AND METHODS}

A retrospective study on consecutive fifty healthy patients, aged between 45 and 75 (average age of 60) undergoing bilateral direct brow lifting surgery, between January 2011 and January 2013 was performed. All patients were men and were treated under local anaesthesia. All patients required a minimally invasive and definitive treatment. International Review Board was not acquired because the research involved the collection of existing data only. Informed consent was obtained from each patient for this study. In all the cases that were included, an upper blepharoplasty had been performed simultaneously. M.P. was the first surgeon in all the procedures. The post-operative follow-up was 12-24 months with an average of 18 months.

The clinical examination focused on (1) the position and stability of the brows, (2) the distance from the top of the brow to the pupil, (3) the length of the forehead, (4) the presence of baldness or anterior hairline thinning, (5) the presence of 'widow's peaks' and other contour irregularities of the hairline, (6) the quality of the forehead skin and also the depth and prominence of rhytids and (7) the heaviness of the tissue around the brow and the thickness of the brow hair.

All patients underwent an eye examination (general eye examination and orthoptic examination). The ophthalmic history and physical examination focused on the presence or absence of lagophthalmos, lid position at rest and ocular surface disorder including dry eye disorder. ${ }^{[1]}$ To avoid an excessive resection of the upper eyelid skin, all patients were preoperatively 'marked' in the upright position for appropriate eyelid skin excision, with the brow maintained in the correct position by the surgeon's fingers. Our general guidelines involve placement of the centre of the brow at the orbital rim level, whereas the lateral portion is positioned just slightly above the orbital rim..$^{[12]}$

\section{Measurements}

Full-size, 1:1, standardised photographs (Frankfort horizontal plane) were taken of each patient 4-6 weeks before surgery. An additional set of photographs was taken postoperatively 12 months after surgery. The post-operative photographs included at least one image with a scale $(\mathrm{cm}$ and $\mathrm{mm})$ to validate measurement accuracy. The distance between a horizontal line passing through the two pupils and the eyebrow upper margin was measured in three positions (medial canthus, pupil and lateral canthus) on each side [Figure 1] as described in previous studies. ${ }^{[5]}$

Indian Journal of Plastic Surgery January-April 2016 Vol 49 Issue 1 
The measurements were recorded and compared. To analyse the statistical variability between pre- and post-operative measurements, the authors applied the paired $t$-test. $P<0.05$ was considered significant. Moreover, at 18-month follow-up visit, each patient was asked to rate the scar quality and the aesthetic results using the Manchester scar scale ${ }^{[13]}$ and a four-point scale (i.e., poor, average, good or excellent), respectively. An evaluation was also made by the surgeon based on the pre- and post-operative clinical photographs.

\section{Technique}

The pre-operative marking is performed with precision while the patient is awake and in the standing position, remembering that the desired post-surgical brow position will not be at the same level of the upper incision, but halfway between the upper and the lower ones [Figure 2]. On the other hand, it is important to be careful to avoid overcorrection because excess skin excision can produce an iatrogenic lagophthalmos. First, the lower incision is performed, maintaining the blade of the scalpel angled but parallel to the axis of the follicles to preserve them. The upper incision must follow the same principles to obtain a perfect joining of the wound. The skin strip was excised avoiding going below the subcutaneous fat. Care was taken to preserve the sensory and motor nerves, which in this area, run below the subcutaneous muscular aponeurotic system. ${ }^{[14]}$ Thus, the orbicular muscle is never incised. A narrow undermining $(7-10 \mathrm{~mm})$ below the eyebrow was performed to further increase tissue compliance [Figure 3a and b]. Vicryl 4/0 (Ethicon, Inc., Somerville, NJ, USA) sutures are used in the subcutaneous layer [Figure 4]. The intradermal suture was performed

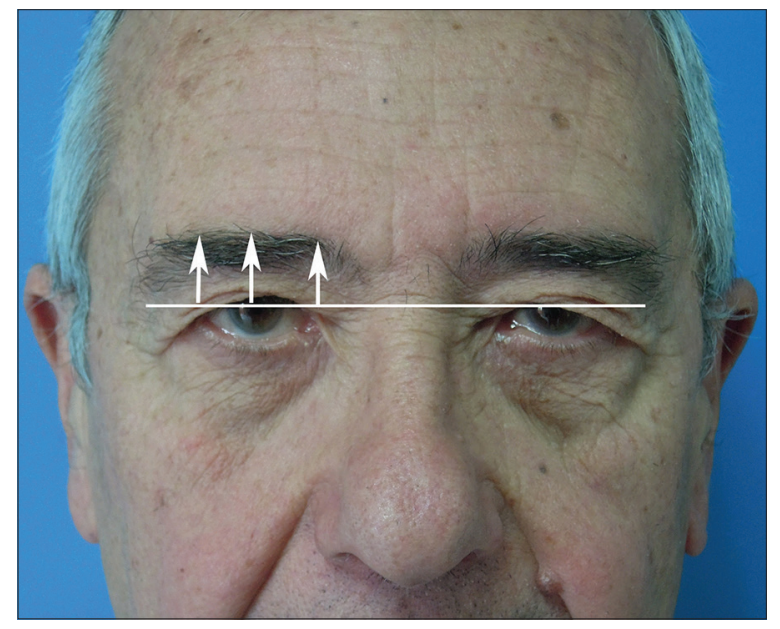

Figure 1: Picture of pre- and post-operative measurements: After drawing the interpupillary line, the distance $(\mathrm{mm})$ between this line and the upper edge of each eyebrow was measured in three points: Medial canthus, pupil and lateral canthus with monocryl 5/0 (Ethicon, Inc., Somerville, NJ, USA) and finally an everting suture in monocryl 5/0 (Ethicon, Inc., Somerville, NJ, USA) was performed to create a raised scar $^{[15]}$ [Figure 5]. In general, three sutures at a distance of $1 \mathrm{~cm}$ between each other are needed. In the present study, an upper blepharoplasty was performed at the same time. Cold compresses and a lightly compressive bandage were placed at the site that were removed the day after surgery. No drainage was required. The sutures in the eyebrow were removed 7 days after surgery.

\section{RESULTS}

The paired $t$-test shows a statistically significant improvement in brow position in all the three portions $(P<0.001)$ [Tables $1 \mathrm{a}$ and $1 \mathrm{~b}$ ]. The whole brow (medial, central and lateral portion) was lifted with direct brow lift. In the left brow, the average initial position was $19.2 \mathrm{~mm}$ in the region near the head of the eyebrow, $19.7 \mathrm{~mm}$ at the body and $20 \mathrm{~mm}$ in the region of the tail. In the right brow, the average initial position was $19.3 \mathrm{~mm}$ in the region near the head of the eyebrow, $20.1 \mathrm{~mm}$ at the body and $20.3 \mathrm{~mm}$ in the region of the tail. The medial region passes to $21.5 \mathrm{~mm}$ on both sides at 12 months after surgery, the body changes to $25.5 \mathrm{~mm}$ (left) and to $25.6 \mathrm{~mm}$ (right), whereas the tail passes to $28.7 \mathrm{~mm}$ on both sides at 1 year.

The quality of the aesthetic result was evaluated by the surgeon as excellent in 46 patients (92\%) and good in four (8\%) patients. For each score given by the surgeon, the patient's assessment score was the same or better [Table 2].

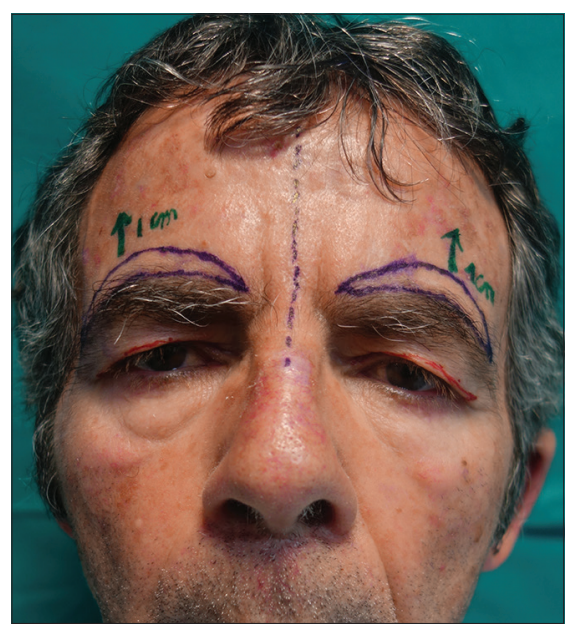

Figure 2: Picture of pre-operative marking while the patient is in the standing position. The skin to remove is drawn. The drawing of the upper blepharoplasty is also visible 


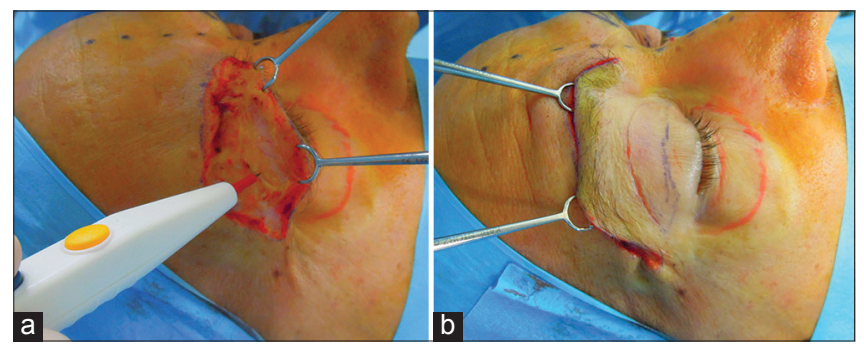

Figure 3: (a) Intra-operative picture to represent a narrow undermining below the eyebrow, (b) this manoeuvre facilitates the lifting procedures and provides a better forces distribution among the underlying tissues avoiding an excess in skin tension

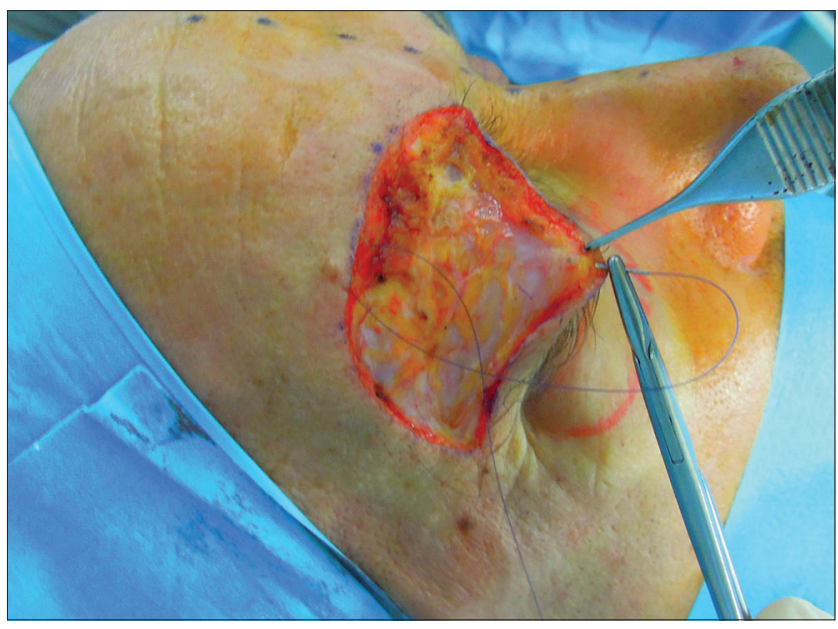

Figure 4: For the subcutaneous suture with vicryl 4/0, generally, three stitches at the distance of $1 \mathrm{~cm}$ between each other are necessary

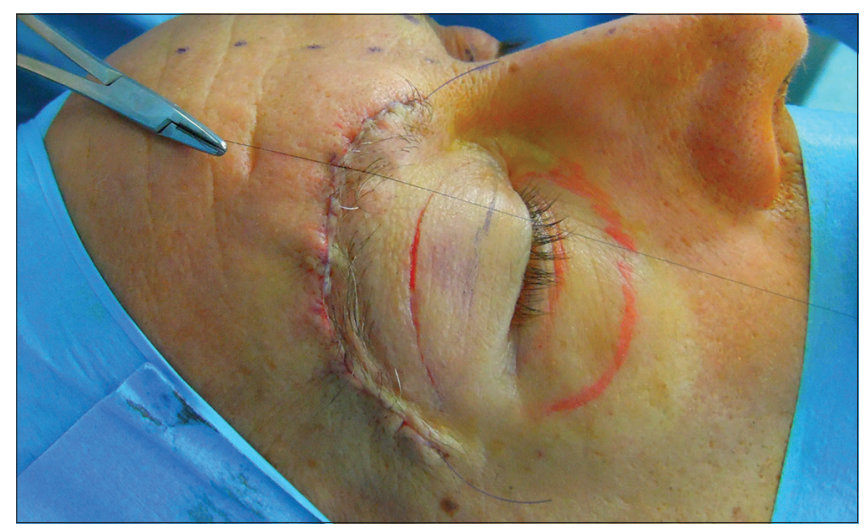

Figure 5: Picture of intradermal suture performed in monocryl 5/0 (Ethicon, Inc., Somerville, NJ, USA) and of the everting suture in monocryl 5/0 (Ethicon, Inc., Somerville, NJ, USA) to maintain raised the scar

The quality of the scars was also evaluated [Table 3]. No major complications or hematomas, infections, numbness, alopecia and excessive scarring were noticed. No dry eyes or lagophthalmos were reported in the ophthalmic post-operative control. The main complication associated with this procedure was the scar visibility in two patients [Figure 6]. Clinical photographs from two patients in our series can be seen in Figures 7 and 8.
Table 1a: Paired t-test on raw measurement data (left side)

\begin{tabular}{|c|c|c|c|c|}
\hline \multicolumn{5}{|c|}{ Left } \\
\hline Measurement & Before & After & Difference & $\begin{array}{c}P \text { (paired } \\
\text { t-test, before } \\
\text { vs. after) }\end{array}$ \\
\hline \multicolumn{5}{|c|}{$\begin{array}{l}\text { MD lateral canthus } \\
\text { to superior brow }\end{array}$} \\
\hline Mean (SD) & $20(1.3)$ & $28.7(0.9)$ & $8.6(1.9)$ & $<0.001$ \\
\hline Median & 19.9 & 28.8 & 8.8 & \\
\hline $\begin{array}{l}\text { Minimum, } \\
\text { maximum }\end{array}$ & $16.8,23.8$ & $26.1,30$ & $1.5,12$ & \\
\hline \multicolumn{5}{|l|}{$\begin{array}{l}\text { MD pupil to } \\
\text { superior brow }\end{array}$} \\
\hline Mean (SD) & $19.7(1.1)$ & $25.5(1.1)$ & $5.6(1.4)$ & $<0.001$ \\
\hline Median & 19.7 & 25.6 & 6.1 & \\
\hline $\begin{array}{l}\text { Minimum, } \\
\text { maximum }\end{array}$ & $16.9,22.3$ & $22.9,27.6$ & $2.3,8.4$ & \\
\hline \multicolumn{5}{|c|}{$\begin{array}{l}\text { MD medial canthus } \\
\text { to superior brow }\end{array}$} \\
\hline Mean (SD) & $19.2(0.9)$ & $21.5(1.2)$ & $2.3(0.9)$ & $<0.001$ \\
\hline Median & 19.3 & 21.4 & 2.4 & \\
\hline $\begin{array}{l}\text { Minimum, } \\
\text { maximum }\end{array}$ & 17,21 & $19.8,24.9$ & $0.7,4.7$ & \\
\hline
\end{tabular}

Table 1b: Paired t-test on raw measurement data (right side)

\begin{tabular}{|c|c|c|c|c|}
\hline \multicolumn{5}{|c|}{ Right } \\
\hline Measurement & Before & After & Difference & $\begin{array}{c}P \text { (paired } \\
\text { t-test, before } \\
\text { vs. after) }\end{array}$ \\
\hline \multicolumn{5}{|c|}{$\begin{array}{l}\text { MD lateral canthus } \\
\text { to superior brow }\end{array}$} \\
\hline Mean (SD) & $20.3(1.7)$ & $28.7(0.9)$ & $8.4(1.7)$ & $<0.001$ \\
\hline Median & 20.2 & 28.7 & 8.7 & \\
\hline $\begin{array}{l}\text { Minimum, } \\
\text { maximum }\end{array}$ & $17.8,29.8$ & $26.3,30$ & $0.2,11.1$ & \\
\hline \multicolumn{5}{|l|}{$\begin{array}{l}\text { MD pupil to } \\
\text { superior brow }\end{array}$} \\
\hline Mean (SD) & $20.1(0.9)$ & $25.6(1.1)$ & $5.7(1.4)$ & $<0.001$ \\
\hline Median & 19.9 & 25.6 & 5.5 & \\
\hline $\begin{array}{l}\text { Minimum, } \\
\text { maximum }\end{array}$ & $17.9,21.8$ & $22.9,27.6$ & $1.9,9.1$ & \\
\hline \multicolumn{5}{|c|}{$\begin{array}{l}\text { MD medial canthus } \\
\text { to superior brow }\end{array}$} \\
\hline Mean (SD) & $19.3(0.9)$ & $21.5(1.1)$ & $2.4(1.8)$ & $<0.001$ \\
\hline Median & 19.6 & 21.4 & 2.1 & \\
\hline $\begin{array}{l}\text { Minimum, } \\
\text { maximum }\end{array}$ & $17.6,21.7$ & $19.8,24.9$ & $0.1,9.1$ & \\
\hline
\end{tabular}

\section{DISCUSSION}

The age-related coarsening of the supraorbital ridge, the soft tissues volume loss and sub-brow fat pad deflation in conjunction with the decreased skin elasticity lead to a progressive three-dimensional collapse of the eyebrows. ${ }^{[16]}$ Different techniques are advocated by various authors; thus, it is critical to understand how each one of these techniques can produce the final cosmetic and functional 
Table 2: Cosmetic results: Surgeon and patient assessments (at 18 months after surgery)

\begin{tabular}{lc}
\hline Cosmetic result & $\boldsymbol{n}^{\circ}$ of patients (\%) \\
\hline Surgeon & \\
Excellent & $46(92)$ \\
Good & $4(8)$ \\
Poor & $0(0)$ \\
Patient & \\
Excellent & $48(96)$ \\
Good & $2(4)$ \\
Poor & $0(0)$ \\
\hline
\end{tabular}

Table 3: Patient's evaluation of quality of the scar

\begin{tabular}{lc}
\hline Quality of the scar & $(\%)$ \\
\hline Poor & $0(0)$ \\
Average & $2(4)$ \\
Good & $10(20)$ \\
Excellent & $38(76)$ \\
\hline
\end{tabular}

outcome. Sex-related differences must be evaluated. In the male patients, the brow is usually flatter in contour and sits lower, along the orbital rim as compared with the female brow. ${ }^{[17]}$ Each patient requires an individualised specific technique. It must be noted that the surface immediately above the orbital rim, where lies the desired brow position, is not flat, but convex inferiorly and slightly concave superiorly. ${ }^{[14]}$ Consequently, a three-dimensional planning of the entire brow: Lateral, middle and medial must be performed. The brow position and shape can be easily modified with the direct approach. In our experience, the direct brow lifting is the first choice in male patients with baldness or high anterior hairline (major or equal to $10 \mathrm{~cm}$ ), thick skin, thick brows, frontal rhytides and with brow asymmetry. ${ }^{[18]}$

No width dissection is required. For this reason, it is suitable in elderly patients wherein it is necessary to combine efficacy and rapidity. The presence of scars needs to be discussed with the patient during the pre-surgical planning. This explanation must emphasise that the scar will be prominent initially, but that it usually fades and progressively disappears, attenuates and blends with the surrounding tissues, sometimes not completely. When a variety of natural transverse forehead lines are present, they provide an ideal location to hide the resulting scar. In our experience, the entire eyebrow must be lifted which is known as 'direct brow lifting', it is the technique of choice. The precise position of selective skin resection increases the control over the shape and elevation of the eyebrow. This is considered to be the main reason for the positive results obtained in the current clinical study.

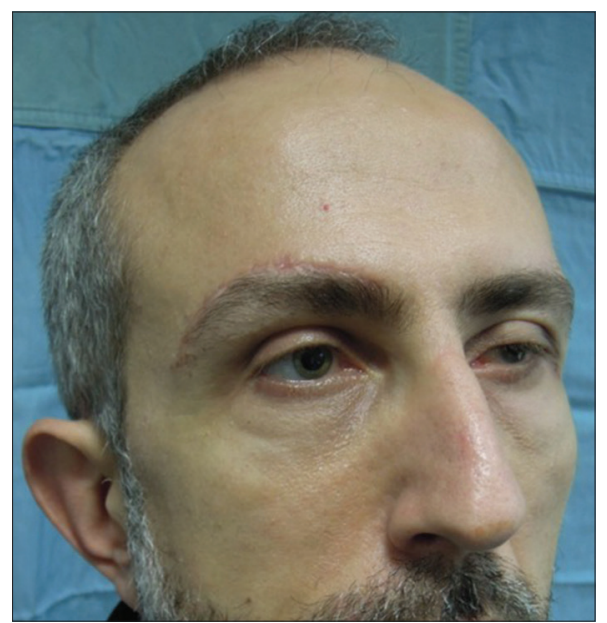

Figure 6: Post-operative aspect in a case with poor scars after a year follow-up. The patient underwent monolateral direct brow lift surgery for severe brow asymmetry (peripheral facial nerve palsy). In this case all the procedures to minimise the scars during surgery were performed, thus it is important to explain this risk to the patient before surgery despite in bald men the direct approach is mandatory

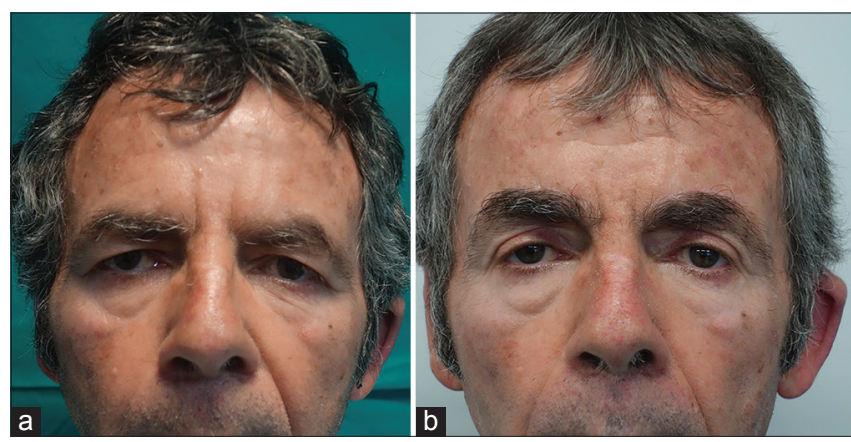

Figure 7: (a) Pre-operative frontal view of a 74-year-old patient with severe brow ptosis and thick brows, (b) 1-year post-operative frontal view of the same patient. The direct brow lift was associated with an upper blepharoplasty

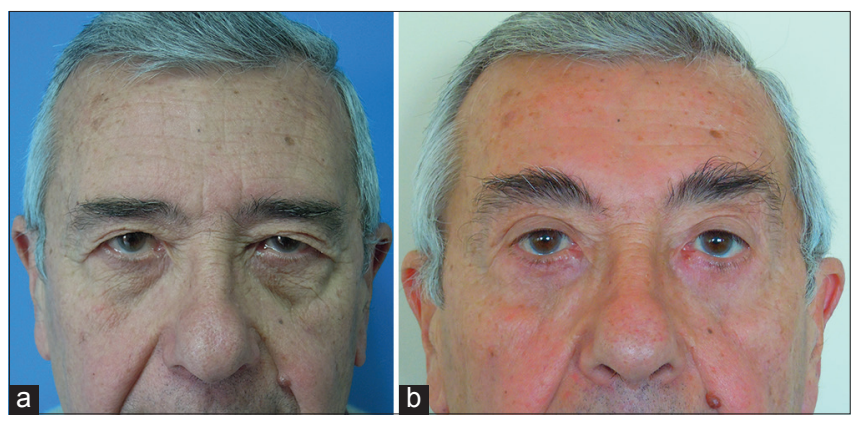

Figure 8: (a) Pre-operative frontal view of a 68-year-old patient with severe brow ptosis and thick brows, (b) 1-year post-operative frontal view of the same patient. The direct brow lift was associated with an upper blepharoplasty

This procedure is very useful in brow height asymmetry because it allows a high degree of control on the vectors and the extent of the lift..$^{[3]}$ In other techniques, ${ }^{[19]}$ with more extensive dissection (coronal endoscopic approach, ${ }^{[20-22]}$ endotine device ${ }^{[8,10,23,24]}$ and suture technique $\left.{ }^{[25]}\right)$, oedema and indirect visualisation do 
not always assure, so there will be a high degree of precision. Moreover, the endoscopic brow lift, despite its distinct advantages such as short incision and no scalp resection, requires endoscopic surgery experience and special equipment. Furthermore, the best candidates for the endoscopic surgery are young patients (between 30 and 40) with a relatively small amount of skin relaxation. ${ }^{[26]}$ In this article, we have not discussed the other aesthetic procedures (thread suspension, botulin toxin A, autologous fat graft and hyaluronic acid fillers) because these treatments are non-surgical alternatives and have different indications (and were not included then). They are reserved for relatively young patients with a small amount of skin relaxation and must be repeated every 6-12 months.

\section{CONCLUSIONS}

In our experience, the direct brow lifting is a useful technique in elderly patients, with thick brows, in males with a high anterior hairline or baldness and when an asymmetry needs correction. This procedure is easy, safe, replicable, requires a short recovery time and is substantially less traumatic when compared to other surgical techniques (coronal approach, endotine device, suture technique and endoscopic surgery).

\section{Declaration of patient consent}

The authors certify that they have obtained all appropriate patient consent forms. In the form the patient(s) has/have given his/her/their consent for his/her/their images and other clinical information to be reported in the journal. The patients understand that their names and initials will not be published and due efforts will be made to conceal their identity, but anonymity cannot be guaranteed.

\section{Financial support and sponsorship} Nil.

\section{Conflicts of interest}

There are no conflicts of interest.

\section{REFERENCES}

1. Avantaggiato A, Girardi A, Palmieri A, Pascali M, Carinci F. Bio-revitalization: Effects of NASHA on genes involving tissue remodeling. Aesthetic Plast Surg 2015;39:459-64.

2. Avantaggiato A, Martinelli M, Palmieri A, Pascali M, Bertuzzi G, Carinci F. Hyaluronic acid: The use of its precursor in skin bio-stimulation. J Biol Regul Homeost Agents 2015;29:647-54.
3. Nahai FR. The varied options in brow lifting. Clin Plast Surg 2013;40:101-4.

4. Guyuron B, Huddleston SW. Aesthetic indications for botulinum toxin injection. Plast Reconstr Surg 1994;93:913-8.

5. Pascali M, Avantaggiato A, Bocchini I, Carinci F, Cervelli V. Comparison among three different fixation techniques in temporal brow lift surgery. J Craniofac Surg 2015;26:906-10.

6. Maas CS, Kim EJ. Temporal brow lift using botulinum toxin A: An update. Plast Reconstr Surg 2003;112 5 Suppl: 109S-12S.

7. Bidros RS, Salazar-Reyes H, Friedman JD. Subcutaneous temporal browlift under local anesthesia: A useful technique for periorbital rejuvenation. Aesthet Surg J 2010;30:783-8.

8. Centurión P, Romero C. Lateral brow lift: A surgical proposal. Aesthetic Plast Surg 2010;34:745-57.

9. Stevens WG, Apfelberg DB, Stoker DA, Schantz SA. The endotine: A new biodegradable fixation device for endoscopic forehead lifts. Aesthet Surg J 2003;23:103-7.

10. Rohrich RJ, Beran SJ. Evolving fixation methods in endoscopically assisted forehead rejuvenation: Controversies and rationale. Plast Reconstr Surg 1997;100:1575-82.

11. Passot RL. Chirurgie Estethique Pure: Techniques et Resultats. Paris: Gaston Dorn et Cie; 1930.

12. Guyuron B, Davies B. Subcutaneous anterior hairline forehead rhytidectomy. Aesthetic Plast Surg 1988;12:77-83.

13. Beausang $\mathrm{E}$, Floyd $\mathrm{H}$, Dunn $\mathrm{KW}$, Orton $\mathrm{Cl}$, Ferguson MW. A new quantitative scale for clinical scar assessment. Plast Reconstr Surg 1998;102:1954-61.

14. Walrath JD, McCord CD. The open brow lift. Clin Plast Surg 2013;40:117-24

15. Botti G, Pelle Ceravolo M. Direct eyebrow lift. In: Midface and Neck Aesthetic Plastic Surgery. Firenze; 2012. p. 250-5.

16. Paul MD. The evolution of the brow lift in aesthetic plastic surgery. Plast Reconstr Surg 2001;108:1409-24.

17. Goldstein SM, Katowitz JA. The male eyebrow: A topographic anatomic analysis. Ophthal Plast Reconstr Surg 2005;21:285-91.

18. Pascali M, Bocchini I, Avantaggiato A, Cervelli V. Our experience with brow ptosis correction: A comparison of 4 techniques. Plast Reconstr Surg Glob Open 2015;3:e337.

19. Georgescu D, Anderson RL, McCann JD. Brow ptosis correction: A comparison of five techniques. Facial Plast Surg 2010;26:186-92.

20. Puig CM, LaFerriere KA. A retrospective comparison of open and endoscopic brow-lifts. Arch Facial Plast Surg 2002;4:221-5.

21. Dayan SH, Perkins SW, Vartanian AJ, Wiesman IM. The forehead lift: Endoscopic versus coronal approaches. Aesthetic Plast Surg 2001;25:35-9.

22. Ellenbogen R. Transcoronal eyebrow lift with concomitant upper blepharoplasty. Plast Reconstr Surg 1983;71:490-9.

23. Berkowitz RL, Jacobs DI, Gorman PJ. Brow fixation with the Endotine Forehead device in endoscopic brow lift. Plast Reconstr Surg 2005;116:1761-7.

24. Pascali M, Gualdi A, Bottini DJ, Botti C, Botti G, Cervelli V. An original application of the Endotine Ribbon device for brow lift. Plast Reconstr Surg 2009;124:1652-61.

25. Tuccillo F, Jacovella P, Zimman O, Repetti G. An alternative approach to brow lift fixation: Temporoparietalis fascia, galeal, and periosteal imbrication. Plast Reconstr Surg 2007;119:692-702.

26. Viksraitis S, Astrauskas T, Karbonskiene A, Budnikas G. Endoscopic aesthetic facial surgery: Technique and results. Medicina (Kaunas) 2004;40:149-55. 